\title{
Thermal Hydraulic Analysis of a Passive Residual Heat Removal System for an Integral Pressurized Water Reactor
}

\author{
Junli Gou, Suizheng Qiu, Guanghui Su, and Douna Jia \\ Department of Nuclear Science and Technology, Xi'an Jiaotong University, Xi'an, Shaanxi 710049, China \\ Correspondence should be addressed to Suizheng Qiu, szqiu@mail.xjtu.edu.cn
}

Received 14 August 2008; Accepted 22 December 2008

Recommended by Xu Cheng

\begin{abstract}
A theoretical investigation on the thermal hydraulic characteristics of a new type of passive residual heat removal system (PRHRS), which is connected to the reactor coolant system via the secondary side of the steam generator, for an integral pressurized water reactor is presented in this paper. Three-interknited natural circulation loops are adopted by this PRHRS to remove the residual heat of the reactor core after a reactor trip. Based on the one-dimensional model and a simulation code (SCPRHRS), the transient behaviors of the PRHRS as well as the effects of the height difference between the steam generator and the heat exchanger and the heat transfer area of the heat exchanger are studied in detail. Through the calculation analysis, it is found that the calculated parameter variation trends are reasonable. The higher height difference between the steam generator and the residual heat exchanger and the larger heat transfer area of the residual heat exchanger are favorable to the passive residual heat removal system.
\end{abstract}

Copyright (C) 2009 Junli Gou et al. This is an open access article distributed under the Creative Commons Attribution License, which permits unrestricted use, distribution, and reproduction in any medium, provided the original work is properly cited.

\section{Introduction}

Integral pressurized water reactor (IPWR) is being considered as one of the next-generation advanced nuclear reactors designed to be inherently safe by naturally and physically passive mechanisms. The primary coolant system components of the IPWRs, composed of the core, the pressurizer, the main coolant pumps (MCPs), and the once-through steam generators (OTSGs), are housed in the reactor pressure vessel (RPV). The adoption of the special in-vessel layout eliminates the pipe connection between those components, and thus the occurrence of large break loss-of-coolant accidents (LBLOCAs) is essentially excluded by the new design. In addition, one of the very important design features of the IPWRs is the simplifications and improvements in the safety systems. Especially, such passive safety systems as passive residual heat removal system (PRHRS) are employed to accomplish the inherent safety functions and mitigate the consequences of the postulated accidents. PRHRS is expected to safely remove the core decay heat, only through natural circulation, in case of both station blackout accident and long-term cooling for repair or refueling.
A literature survey reveals that there have been many experimental and numerical investigations on the characteristics of different PRHRSs. The Westinghouse advanced passive PWRs, AP-600, AP-1000, and EP-1000 (IAEATECDOC-1391, 2004; Adomaitis et al. [1]; Reyes and Hochreiter [2]; Zhang et al. [3]) adopt passive core cooling system (PXS) to protect the plant against reactor coolant system (RCS) leaks and ruptures of various sizes and locations. The PXS includes a 100\% capacity passive residual heat removal heat exchanger (PRHR HX), which satisfies the safety criteria for loss of feedwater, feedwater and steam line breaks. The PRHR HX, immersed in the in-containment refueling water storage tank (IRWST), is connected through the cold leg and hot leg to the core. The IRWST water volume is sufficient to absorb decay heat for more than 1 hour before the water begins to boil. Once boiling starts in the IRWST, the steam passes to the containment and condenses on the inner surface of the steel containment vessel, and then drains by gravity back into the IRWST. The PRHR HX and the passive containment cooling system (PCCS) provide indefinite decay heat removal capability with no operator action required. The theoretical and experimental 
investigations on the PXS characteristics of AP600 indicate that the design of the PRHRS is feasible and rational.

The PRHRSs via the secondary side of the steam generators for WWER-1000/V-392 and WWER-640/V-407 plants (Hyvärinen [4]; IAEA-TECDOC-1391, [5]; Krepper [6]; Mousavian et al. [7]) are intended to remove decay heat from the reactor in a case of a station blackout with intact primary and secondary circuits, and to depressurize the RCS under a small break LOCA. The PRHRS of V-392 consists of four independent trains, each of which has pipelines for steam supply and removal of condensate, valves, and an aircooled heat exchanger installed outside the containment. The steam generated in the steam generators due to the heat released in the reactor condenses in the air-cooled heat exchanger and rejects its heat to the ambient air. The motion of the cooling medium takes place in natural circulation. While in the V-407 design, the PRHRS removes the heat to the heat exchangers immersed to the emergency heat removal tanks, which are installed outside the containment. The water inventory in the tanks is sufficient for the longterm heat removal (at least 24 hours) and can be replenished if necessary. The experimental investigation and calculation analyses show that the PRHRS for WWER can safely remove the decay heat in case of the station blackout accident and enhance the inherent safety of the plant. The experimental investigations have confirmed the design function of the passive safety means proposed and also created the necessary experimental database for modeling by the system thermohydraulic codes. Further investigations are being planned for additional verification of the passive safety systems and for the optimization of their design.

The PRHRS (Su et al. [8, 9], Qiu et al. [10], Zejun et al. [11]) for Chinese advanced PWR (AC-600) is used to remove the decay heat in the event of a station blackout by natural circulation. It may also be effective in a main steam pipe rupture or loss of feedwater event. The system consists of two independent trains, each of them being connected to the reactor coolant loops via the secondary side of the respective steam generator. Each train has a feedwater tank, an air cooler located in a chimney outside the containment, and piping (and valves) for steam and condensate circulation. The air cooler with the help of chimney rejects the core decay heat transferred from the steam generators into the atmosphere. Based on the experimental investigations, semiempirical theoretical model related to height between heat resource and heat sink has been established which can be applied to the system arrangement design for the PRHRS of Chinese advanced PWR. Transient experiment also provides the basis for the startup mode of the PRHRS. Furthermore, a way to avoid potential water hammer in the feedwater tank has been identified. Computer code MISAP2.0 has been developed with self-reliance copyright, which is a useful tool for the PRHRS design.

The PRHRS for SMART (Chang et al. [12]; Chung et al. [13]; Chung et al. [14]; Chung et al. [15]), a small modular integral-type pressurized water reactor developed by KAERI, is also a steam generator secondary side decay heat removal system. Two of the four independent PRHRS trains are sufficient to remove the decay heat. Each train is composed of a compensating tank pressurized by nitrogen, a heat exchanger immersed in an in-containment refueling water tank, valves and piping for steam and condensate. The compensating tank makes up the water volume change in the passive residual heat removal system and holds the water inventory for the filling system pipelines during a cooldown transient. The check valves are installed on the pipelines between the compensating tank and the heat exchanger outlet to keep the water from leaving the compensating tank in the first instants of a cooldown, which would prevent a natural circulation from being developed. The refueling water tank is located high enough above the steam generator to remove the heat transferred from the primary side in the steam generator by a natural convection when the secondary system loses its heat removal capability. The water in the refueling water tank is heated, boiled, and eventually evaporated into the atmosphere. The water inventory in the refueling water tank can remove the heat for 36 hours at least without any operator actions to respond to the design basis events. The heat transfer characteristics and the natural circulation performance of the PRHRS for the SMART have been experimentally investigated in the VISTA facility, and the experimental results have been analyzed using a bestestimated system analysis code, MARS. The comparison of the experimental data and the theoretical prediction shows good agreement accept for some parameters, such as the fluid temperature in the PRHRS condensate line. It seems that it is due to an insufficient heat transfer modeling in the pool such as the refueling water tank in the MARS calculation. Besides, PRHRSs for other reactors have been developed in the last decade (Iwamura et al. [16]; Samoilov et al. [17]; Peng et al. [18]; Jinling and Yujun [19]; Kusunoki et al. [20]; Xinian et al. [21]; Carelli et al. [22]).

A detailed review of the related literatures indicates that the PRHRSs are quite different from one another in design for different PWRs. The merits and demerits of different PRHRSs are very difficult to be evaluated. Both the test facilities for the corresponding PRHRSs and the commercial analysis codes (like Relap, Retran, etc.) have their own limitations. It is evident that due to the complexity of the thermal hydraulic process involved in the PRHRSs with their small inherent natural driving forces (i.e., gravity, natural circulation, etc.), experimental and theoretical investigations have to be performed for each specific design. Validated computer codes must be developed to support the expected operational performance. Consequently, considering the design features and operation performances of a new type of PRHRS, systematic analyses on the thermal hydraulic characteristics of it should be performed in detail at the conceptual design stage from both experimental and analytical points of view.

In the present paper, a theoretical investigation on the thermal hydraulic characteristics of a new type of PRHRS, which is connected to the reactor system via the secondary side of the steam generator, for an integral pressurized water reactor is conducted. With three-interknited natural coolant circulation loops, the core decay heat should be safely removed to an ultimate heat sink, a water pool (WP) with a large enough size. In order to estimate the thermal hydraulic 


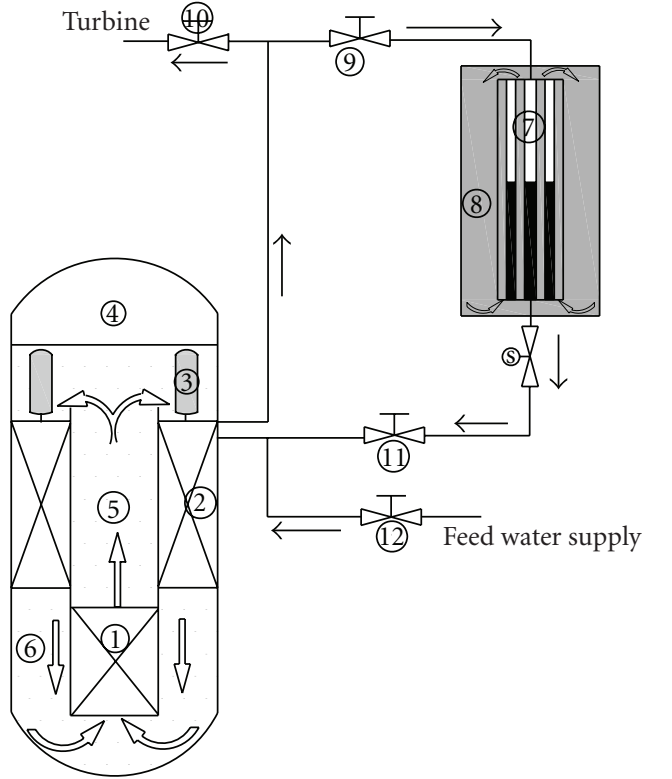

$\begin{array}{ll}\text { 1. Core } & \text { 5. Riser } \\ \text { 2. OTSG } & \text { 6. Downcomer } \\ \text { 3. MCP } & \text { 7. Heat exchanger } \\ \text { 4. Pressurizer } & \text { 8. Water pool }\end{array}$

(a)

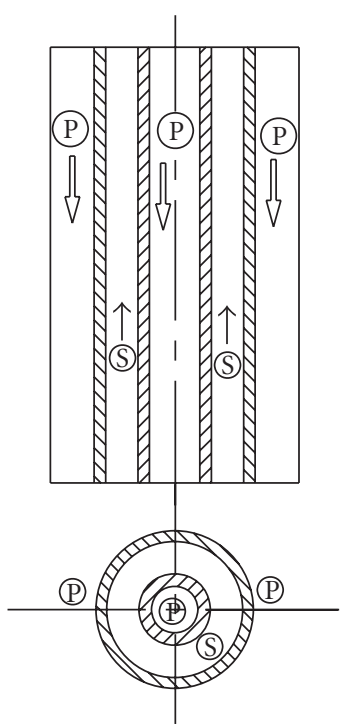

9. Check valve

10. Main steam valve

11. Isolation valve

12. Feed water valve
(P) Primary fluid flow

(S) Secondary fluid flow

(b)

FIgURE 1: Schematic diagram of the PRHRS and OTSG heat transfer tubes.

characteristics and evaluate the heat removal capacity of the PRHRS, a one-dimensional two-phase flow model and a simulation code (SCPRHRS) are developed. The model is based on the fundamental conservation principles, namely, the mass, momentum, and energy conservation equations. System component models are included according to the special design features of it. All possible flow and heat transfer conditions are considered and the corresponding optional models are supplied in the simulation code. Using the code, the analyses results of the PRHRS transient behavior are presented in this paper.

\section{System Description}

The layout of the primary coolant system components and the PRHRS of this IPWR are shown in Figure 1(a). The primary coolant system components, including a core, a pressurizer, 2 main coolant pumps (MCPs), and 12 oncethrough steam generators (OTSGs), are contained in the reactor pressure vessel (RPV). The reactor core is located at the bottom of the RPV. The MCPs and the OTSGs are installed symmetrically in the annular space between the reactor barrel and the RPV. This configuration results in an integral and compact system. There is a long riser on the top of the core outlet to enhance the natural circulation capacity. At the same time, a natural circulation by-pass valve, installed between the inlet and the outlet of each MCP, is designed to reduce the natural circulation form loss.

Under forced circulation conditions, the natural circulation by-pass valve is kept closed and the primary coolant is driven by the MCPs to circulate along the primary circuit. The primary coolant enters the core from the lower plenum. After being heated, the coolant flows out of the core and upwards through the riser. Then, the coolant is pumped by the MCPs, located at the exit of the riser, and flows through the annular cavity on top of the primary entry of the OTSGs. Subsequently, it flows downwards through the primary side of the OTSGs, cooled by the secondary coolant and the downcomer until reaching the lower plenum. Finally, it flows back into the core and recirculates continually along the flow path. The heat transfer element of the OTSGs has a straight annular channel, composed of two concentric circular tubes with different diameters (see Figure 1(b)). In the steam generator, the secondary coolant flows upwards in the annular channel and is bilaterally heated by the primary coolant, which flows downwards in the shell-side of the annular channel outer tube and the inner tube of the annular channel, respectively.

There are two sets of independent residual heat removal system with identical characteristics. They are installed outside the reactor pressure vessel and connected to the secondary circuit loops (Figure $1(\mathrm{a})$ ). The residual heat exchanger, which has a straight tubular bundle type, is immerged in a water pool with very large size. Under normal operating conditions, the heat exchanger is filled with water and isolated by a check valve and an isolation valve. The PRHRS removes the core decay heat by natural circulation under station blackout accident as well as in the case of longterm cooling for repair or refueling. After a reactor trip, the PRHRS will start to work automatically without any active 
operation. The shutdown signal from the reactor control system makes the turbine tripped, the main steam valves and the feed water valves closed. The forced circulation in the primary loop turns into natural circulation. At the same time, the check and isolation valves open automatically and the water in the heat exchanger enters the secondary side of the OTSGs by gravity. After exiting the steam generator as superheated or saturated fluid, the secondary coolant enters the residual heat exchanger and flows downwards in the tube-inside, where it is cooled by the shell-side water in the water pool and condensed to subcooled water. Finally, the condensate flows back to the steam generator. Also, the natural circulation will establish in the water pool because of the continual heating from the secondary coolant. Consequently, the residual decay heat of the core is passively removed to the ultimate heat sink through three-interknited natural circulation loops, namely, (1) the primary circulation loop composed of the core, the primary side of the OTSGs, and the connecting plenums; (2) the secondary circulation loop including the secondary side of the OTSGs, the tubeinside of the heat exchangers, and the connecting pipes and plenums; (3) the third circulation loop in the water pool.

\section{Theoretical Model}

The basic field model is based on the fundamental conservation principles: the mass, momentum, and energy conservation equations. With the assumption of one-dimensional flow, these equations, including single-phase and twophase conservative equations, can be easily found in the reference (Collier and Thome [23]). The characteristics of the theoretical model are introduced in the following in detail.

3.1. Core Power. The core power is calculated using the decay heat equation and point neutron kinetics equation with six groups of delayed neutron (Pingan et al. [24]). Each group has its own yield and decay constant. The reactivity feedback caused by the temperature change of the moderator and the fuel is specially considered. The axial power distribution is specified by a profile supplied. At the same time, the power distribution in the radial direction is assumed to be uniform.

\subsection{System Components Model}

3.2.1. Mass Flow Rate of the Primary Loop. By integrating the momentum conservative equation along the primary loop, the mass flow rate equation is given by

$$
\begin{aligned}
\frac{\partial W_{P}}{\partial \tau} \oint \frac{1}{A} d z= & -\oint \frac{\partial P}{\partial Z} d z-\oint \frac{1}{A} \frac{\partial}{\partial z}\left(\frac{W_{P}^{2}}{\rho A}\right) d z \\
& -\oint \rho g d z-W_{P}^{2} \sum_{i=1}^{n}\left(\frac{c}{2 \rho A^{2}}\right)_{i} \\
& -W_{P}^{2} \oint f \frac{1}{2 D_{e} \rho A^{2}} d z .
\end{aligned}
$$

In fact, the second terms on the right hand of (1) can be eliminated. By introducing natural circulation driving head $B_{P},(1)$ is simplified as follows:

$$
\frac{\partial W_{P}}{\partial \tau}=\frac{\left(P_{\text {pump }}+B_{P}-\Delta P_{\operatorname{loc}_{P}}-\Delta P_{f_{P}}\right)}{\oint(d z / A)},
$$

where $\Delta P_{\text {loc }_{p}}$ and $\Delta P_{f_{p}}$ are the local pressure drop and the friction pressure drop along the primary loop, respectively; $P_{\text {pump }}$ is the pressure head of the MCP. $B_{P}, \Delta P_{\text {loc }_{P}}$, and $\Delta P_{f_{p}}$ are defined by

$$
\begin{gathered}
P_{\text {pump }}=\rho g H_{\text {pump }}, \\
B_{P}=-\oint \rho g d z, \\
\Delta P_{\text {loc } P_{P}}=W_{P}^{2} \sum_{i=1}^{n}\left(\frac{c}{2 \rho A^{2}}\right)_{i} \\
\Delta P_{f_{P}}=W_{P}^{2} \oint f \frac{1}{2 D_{e} \rho A^{2}} d z .
\end{gathered}
$$

The pressure head of the MCP during the transient process is a very important parameter to calculate the mass flow rate of the primary loop. However, the pressure head of the MCPs reduces rapidly to zero due to the small inertia rotation after a reactor trip. Moreover, as mentioned above, the MCPs stop and the by-pass valves are opened to enhance the natural circulation under natural circulation conditions. Because the local form loss coefficient of the by-pass valve is much less than that of the MCP, most of the primary coolant flows through the by-pass valve. The relationship between the local pressure drop of the MCP and the by-pass valve is expressed by

$$
\Delta p_{\text {pump }}=\Delta p_{v}
$$

That is,

$$
\frac{1}{2} c_{\text {pump }} \frac{W_{\text {pump }}^{2}}{A_{\text {pump }}^{2} \rho}=\frac{1}{2} c_{v} \frac{W_{v}^{2}}{A_{v}^{2} \rho} .
$$

While

$$
W_{p}=W_{\text {pump }}+W_{v}
$$

Substituting (5) and (6) into (4), the local pressure drop of the MCP is

$$
\Delta p_{\text {pump }}=\frac{1}{2} c_{\text {pump }} \frac{W^{2}}{\left(1+A_{v} \sqrt{c_{\text {pump }} / c_{v}} / A_{\text {pump }}\right)^{2} A_{\text {pump }}^{2} \rho} .
$$

3.2.2. Mass Flow Rate of the Secondary Loop. Similarly, by integrating the momentum conservative equation along the secondary loop, the mass flow rate equation is given by

$$
\frac{\partial W_{s}}{\partial \tau}=\frac{\left(B_{s}-\Delta P_{\text {loc }_{s}}-\Delta P_{f_{s}}\right)}{\oint(d z / A)}
$$


where $B_{s}, \Delta P_{\text {loc }_{s}}$, and $\Delta P_{f_{s}}$ are expressed by

$$
\begin{gathered}
B_{s}=-\oint \rho g d z, \\
\Delta P_{\mathrm{loc}_{s}}=W_{s}^{2} \sum_{i=1}^{n}\left(\frac{c}{2 \rho A^{2}}\right)_{i} \\
\Delta P_{f_{s}}=W_{s}^{2} \oint f \frac{1}{2 D_{e} \rho A^{2}} d z .
\end{gathered}
$$

3.2.3. Mass Flow Rate of the Third Loop. Because the size of the water pool is large enough, an assumption, that the change of the pool water temperature can be neglected, is rational. Similarly, by applying the momentum conservative equation, the mass flow rate of the third loop is written as

$$
\frac{\partial W_{t}}{\partial \tau}=\frac{\left(B_{t}-\Delta P_{\mathrm{loc}_{t}}-\Delta P_{f_{t}}\right)}{\sum_{i=1}^{k}(\Delta z / A)_{i}},
$$

where $B_{t}, \Delta P_{\text {loc }_{t}}$, and $\Delta P_{f_{t}}$ are defined as follows:

$$
\begin{aligned}
B_{t} & =\rho_{p} g L-\sum_{j=1}^{k}(\rho g \Delta z)_{j}, \\
\Delta P_{\text {loc }_{t}} & =W_{t}^{2} \sum_{i=1}^{n}\left(\frac{c}{2 \rho A^{2}}\right)_{i} \\
\Delta P_{f_{t}} & =W_{t}^{2} \sum_{j=1}^{k}\left(\frac{f \Delta z}{2 D_{e} \rho A^{2}}\right)_{j} .
\end{aligned}
$$

It is noted that the equations for mass flow rate calculation of the three loops are simplified equations with an assumption of constant flow rate along the circuit. This simplification may cause inaccuracy especially in case of two-phase flow. However, this simplified model has been successfully adopted in our previous investigations ( $\mathrm{Su}$ and Guo [8], Qiu et al. [10], Zejun et al. [11], Tian et al. [25, 26]). The comparisons of our results with those of RETRAN02 and RELAP/MOD3 gave good agreements. So, using the simplified model in this calculation is still believed to be feasible for the conceptual design of the PRHRS.

3.2.4. Pressure of the Secondary Loop. Under normal operation condition with rated core power, the spatial variation of the pressure in the secondary loop cannot be neglected because of the large pressure drop from the inlet to the outlet of the OTSG secondary side (about 1.5 MPa). However, in case of natural circulation, the spatial pressure difference of the secondary loop becomes very small as a result of the loss of feed water pump head. Thus, an assumption, that the spatial variation of the pressure in the secondary loop is negligible, can be made. Consequently, by integrating the mass continuity equation along the secondary loop, the pressure equation of the secondary loop can be written as

$$
\sum_{i=1}^{n}\left[\left(\frac{\partial \rho}{\partial h} \frac{\partial h}{\partial \tau}+\frac{\partial \rho}{\partial p} \frac{\partial p}{\partial \tau}\right) A \cdot \Delta Z\right]_{i}=-\oint \frac{\partial W}{\partial z} d z
$$

TABLE 1: Heat transfer correlations.

\begin{tabular}{lcc}
\hline Flow regime & Correlation & Reference \\
\hline Single-phase water & & \\
$\quad$ Laminar & Collier & {$[27]$} \\
Transition & Interpolation & \\
Turbulent & Sieder-Tate & {$[28]$} \\
Subcooled boiling & Jens and Lottes & {$[23]$} \\
Saturated boiling & Chen & {$[23]$} \\
Transition/film boiling & Groeneveld & {$[29]$} \\
Superheated vapor & Sieder-Tate & {$[28]$} \\
Condensation & Shaha & {$[30]$} \\
\hline
\end{tabular}

Practically, the right-hand side of (12) equals zero. Thus, (12) is simplified as

$$
\frac{\partial p}{\partial \tau}=-\frac{\sum_{i=1}^{n}\left(\rho^{2} A \cdot \Delta Z(\partial v / \partial h)(\partial h / \partial \tau)\right)_{i}}{\sum_{i=1}^{n}\left(\rho^{2} A \cdot \Delta Z(\partial v / \partial p)\right)_{i}} .
$$

3.2.5. Tube Wall Heat Transfer. Because of the very small thickness of the tube wall, lumped parameter method is used to calculate the wall heat transfer. Ignoring the axial conduction heat transfer, the tube wall heat transfer equation is expressed by

$$
m C_{p} \frac{\partial T_{w}}{\partial \tau}=H_{1} A_{1}\left(T_{1}-T_{w}\right)-H_{2} A_{2} \cdot\left(T_{w}-T_{2}\right)
$$

where $T_{w}$ is the average temperature of the tube wall; $H_{1}$ and $\mathrm{H}_{2}$ are heat transfer coefficients of the two surfaces of the wall, respectively; $A_{1}$ and $A_{2}$ are heat transfer area of the two surfaces of the wall, respectively; $T_{1}$ and $T_{2}$ are the fluid temperatures, respectively.

3.2.6. Pipe and Plenum. In the PRHRS, there are pipes and plenums to connect the major components. With an assumption of thermal isolation, the energy conservative equation of them can be expressed by

$$
M \frac{d h}{d \tau}=W\left(h_{\text {in }}-h\right)
$$

3.2.7. Heat Transfer and Frictional Coefficient Correlations. The dominant heat transfer of the primary loop and the third loop is single-phase mode, and the modes of the secondary loop are single-phase and boiling heat transfer in the OTSG and condensation and single-phase heat transfer in the heat exchanger. According to the corresponding flow regimes, appropriate heat transfer and frictional coefficient correlations are selected. Two-phase frictional multiplier is used to calculate the two-phase flow pressure drop, that is,

$$
f_{\mathrm{tp}}=f_{\mathrm{lo}} \cdot \Phi_{\mathrm{tp}}^{2}
$$

The involved heat transfer and frictional coefficient correlations are listed in Tables 1 and 2, respectively.

3.3. Nodalization of the PRHRS. In order to numerically simulate the thermal hydraulic characteristics of the PRHRS, 
TABLE 2: Frictional coefficient correlations.

\begin{tabular}{lcc}
\hline Flow regime & Correlation & Reference \\
\hline Single phase & & \\
Laminar flow & Darcy & {$[24]$} \\
Transition flow & 0.048 & \\
Turbulent flow & Blasius & \\
Two phase & & \\
Homogeneous model & & {$[31]$} \\
Drift flux model & Chisholm & {$[32]$} \\
\hline
\end{tabular}

the whole system shown in Figure 1 is divided into many control volumes and junctions according to the different geometrical and heat transfer conditions. Figure 2 schematically shows the nodalization of the PRHRS. The primary circuit model used in the thermal hydraulic analysis consists of a core, a steam generator, a pump, a pressurizer, a downcomer, and plenums. The modeling of the PRHRS is composed of a steam generator, a heat exchanger, a water pool, pipes, plenums, and valves. In the core, the steam generator and the heat exchanger, fine control volume division is used to properly predict the heat transfer phenomena. The number of the control volume can be easily changed for different calculation requirements.

\section{Numerical Method and Code Description}

In order to theoretically analyze the thermal hydraulic characteristics of the PRHRS, the above equations need to be numerically solved. Through discretizing the spatial terms of the above differential equations, they have a form in common as follows:

$$
\begin{gathered}
\frac{d \vec{y}}{d \tau}=\vec{f}\left(t, \vec{y}, \vec{y}^{\prime}\right), \\
\vec{y}\left(\tau_{0}\right)=\vec{y}_{0} .
\end{gathered}
$$

It is noted that numeric solution of these equations is an initial value problem of nonlinear first-order ordinary differential equations with variable coefficients. These differential equations used to describe the reactor system usually have large stiffness. It is shown that, using the traditional algorithm such as the Runge-Kutta algorithm to solve the stiff differential equations may result in failure in some cases. In the present paper, Gear algorithm (Yuan Zhaoding [33]; Su et al. [34]; Tian et al. [25]; Yun et al. [35]), which is a backward difference implicit algorithm and especially suitable for solving stiff differential equations, is adopted to solve the above equations.

Base on the theoretical model and solution method, a simulation code, SCPRHRS, is developed. The code is in Fortran 90 format and can be maintained in the PC/Windows environment. For convenient maintenance and readability of the code, modular programing techniques are adopted. The main function modules are data input module, initialization module, transient module, derivative module, numerical
TABLE 3: Main parameters of SG and PRHRS.

\begin{tabular}{lc}
\hline Parameter & Value \\
\hline Initial core power & $160 \mathrm{MW}$ \\
\hline Steam generator & \\
Primary operation pressure & $15.5 \mathrm{MPa}$ \\
Primary mass flow rate & $980 \mathrm{~kg} / \mathrm{s}$ \\
Primary inlet temperature & $295^{\circ} \mathrm{C}$ \\
Primary outlet temperature & $265^{\circ} \mathrm{C}$ \\
Secondary mass flow rate & $60 \mathrm{~kg} / \mathrm{s}$ \\
Secondary inlet temperature & $60^{\circ} \mathrm{C}$ \\
Secondary outlet temperature & $270^{\circ} \mathrm{C}$ \\
Secondary pressure & $3.0 \mathrm{MPa}$ \\
Diameter of inner tube & $8 \times 1 \mathrm{~mm}$ \\
Diameter of outer tube & $12 \times 1 \mathrm{~mm}$ \\
Length of the tube & $2.0 \mathrm{~m}$ \\
\hline Passive heat removal system & \\
Secondary initial temperature & $30^{\circ} \mathrm{C}$ \\
Secondary initial pressure & $3.0 \mathrm{MPa}$ \\
Diameter of tube & $25 \times 2.5 \mathrm{~mm}$ \\
Length of the tube & $2.0 \mathrm{~m}$ \\
Water temperature of WP & $30^{\circ} \mathrm{C}$ \\
WP pressure & $0.1 \mathrm{MPa}$ \\
\hline
\end{tabular}

method module, auxiliary module, thermophysical property module, output module, and so forth. All involved heat transfer and friction coefficient correlations are supplied in the auxiliary module. Derivative module is used to calculate the right-hand side of the differential equations (like (17)). Modification of these modules or addition of new modules can be easily done for different calculation requirements. The calling relationship of these modules and the N-S flowchart of SCPRHRS are shown in Figures 3 and 4, respectively.

\section{Initial Conditions}

The major structural and initial parameters used for the theoretical analysis are shown in Table 3. There are two sets of PRHRS, each of which has the same characteristics and is connected with four OTSGs, respectively. In the calculation, because of the large heat capacity of the water pool, an assumption, that the inlet temperature of the third loop is constant, is made. Before the PRHRS starts up, the reactor is under a normal operating steady state, and the PRHRS and the third loop do not work.

\section{Results and Discussion}

6.1. Transient Thermal Hydraulic Characteristics of PRHRS. Figure 5 shows the core power, the heat transferred to secondary side of the steam generator, and the heat transferred to the WP after the reactor is shut down. It can be seen that the core power and the heat transferred to the secondary side of the steam generator decrease rapidly at the initial stage and at about 20 seconds they begin to decrease slowly. 


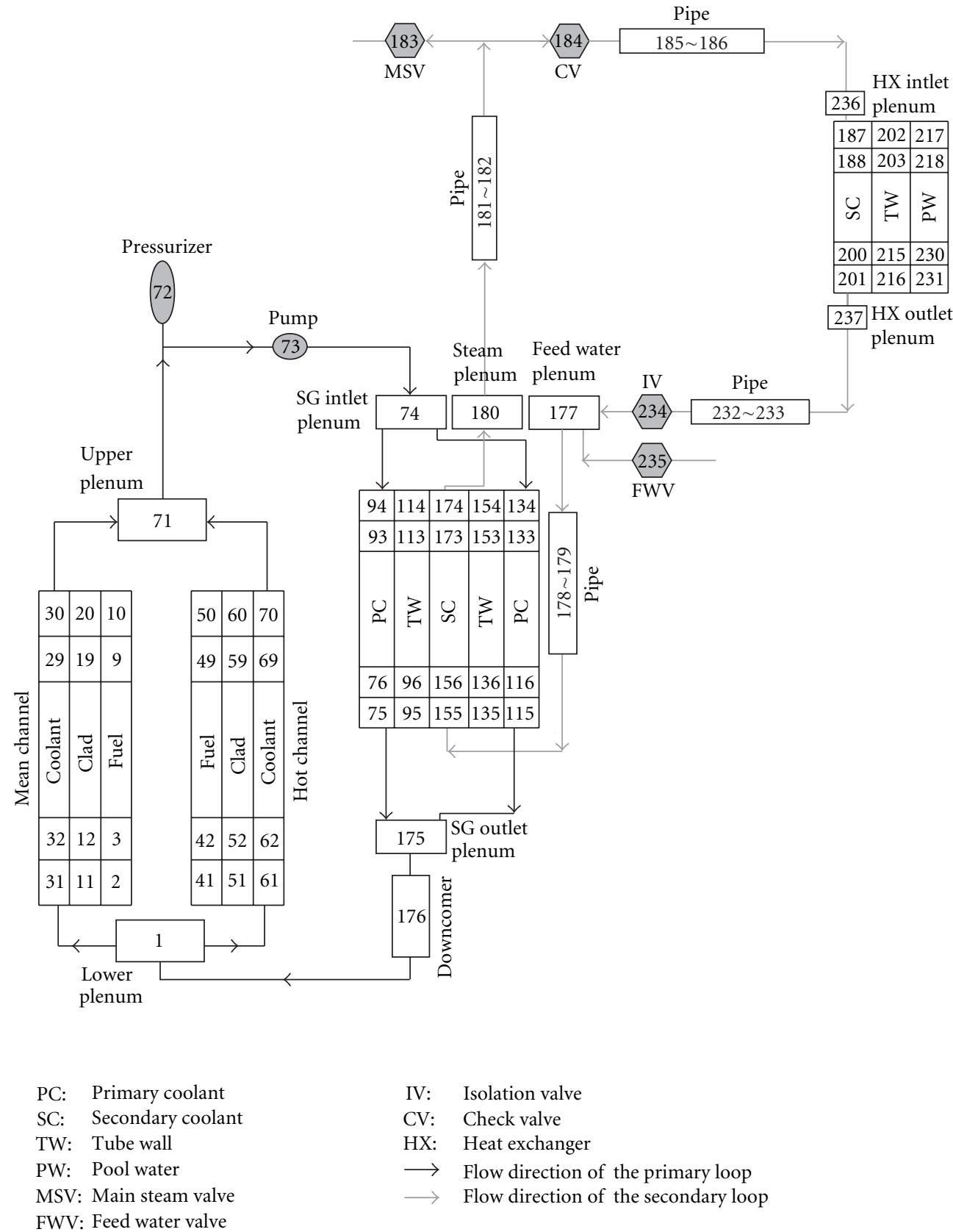

FIGURE 2: SCPRHRS nodalization for the PRHRS.

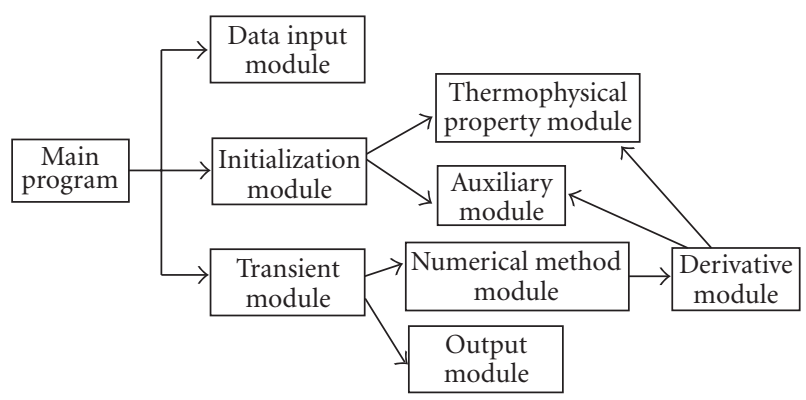

FIGURE 3: Calling relationships of the modules.

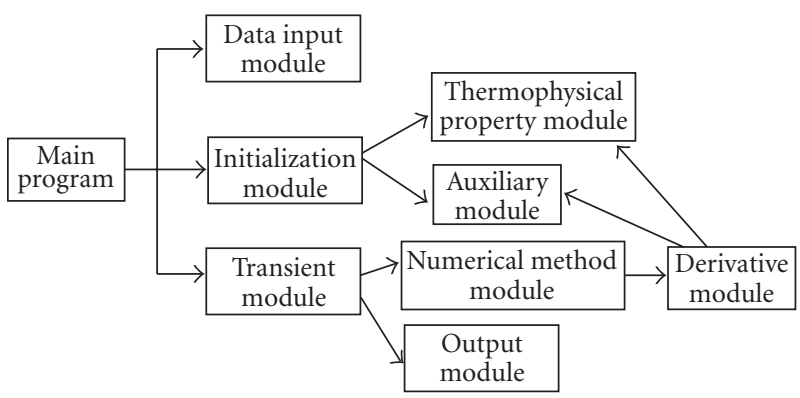

Figure 4: N-S flowchart of the code. 


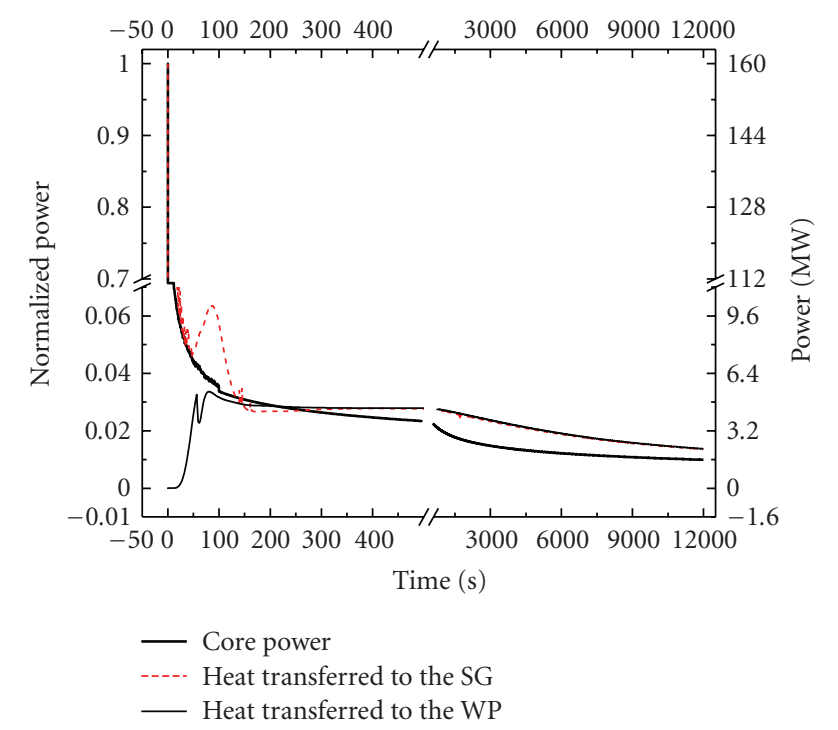

FIGURE 5: Decay power and heat transferred in the SG and PRHRS.

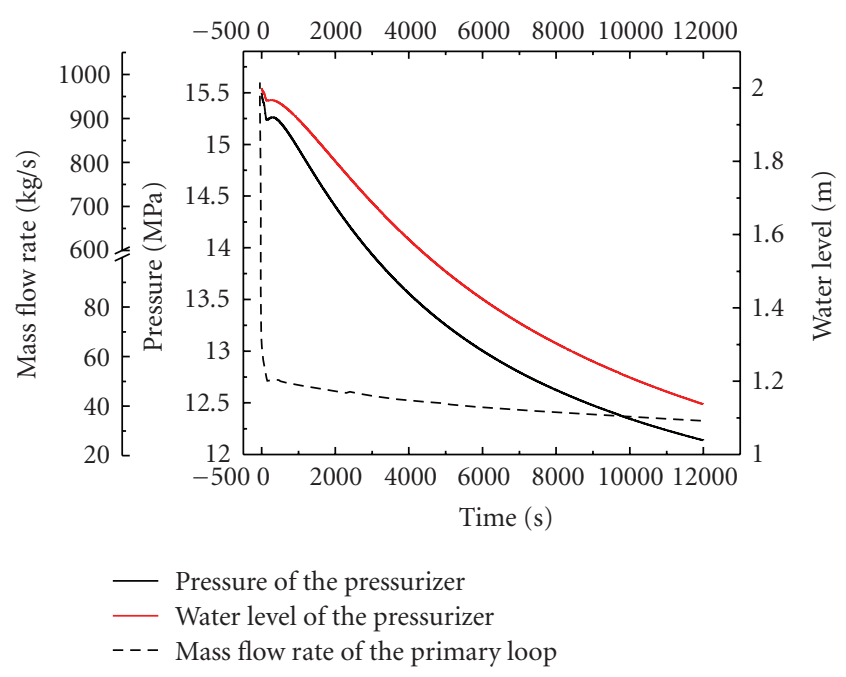

Figure 6: Mass flow rate of the primary loop, pressure, and water level of the pressurizer.

The heat transferred to the WP is under a very low level at the beginning of the transient process. With the establishment of the natural circulation in the PRHRS, the heat transferred to the WP increases gradually, and at about 150 seconds it becomes higher than that transferred to the secondary side of the steam generator. At about 300 seconds, the heat transferred to the secondary side of the steam generator is higher than the core power. It can be assumed that after this point the decay heat can be removed safely.

After the reactor is shut down, the control system makes the MCPs stopped, the forced circulation of the primary loop transits to natural circulation. The mass flow rate of the primary loop is shown in Figure 6. Because of the rapid decrease of the core power, the pressure and the water level

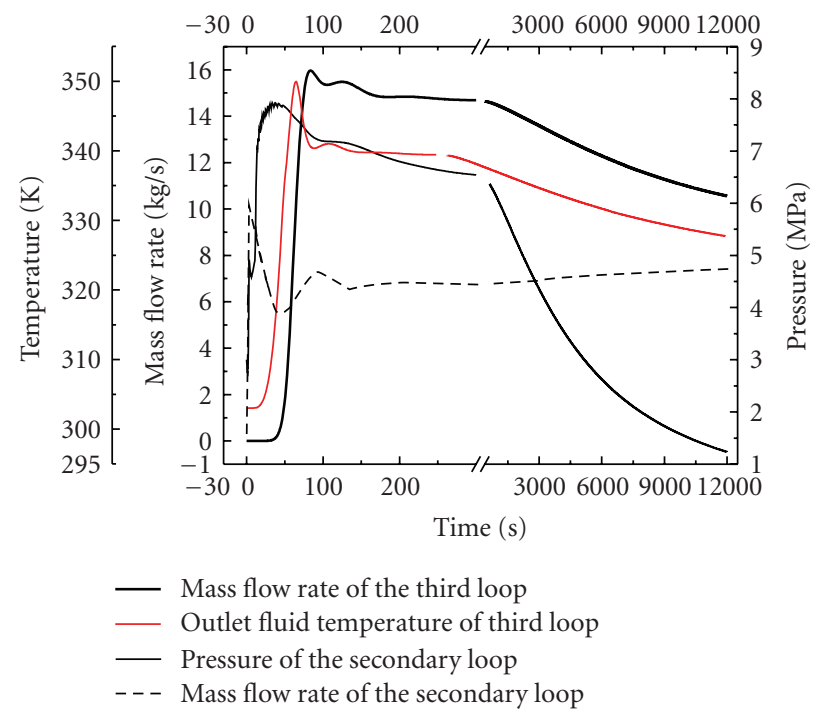

FIGURE 7: Mass flow rate and pressure of the secondary loop, mass flow rate and outlet temperature of the third loop.

of the pressurizer decrease immediately at the initial stage. On the other hand, with the increase of the secondary loop pressure (see Figure 7), the saturated temperature of the secondary loop increases correspondingly. The temperature difference of the two sides of the steam generator becomes smaller, which leads to the degradation of the heat transfer of the steam generator. Consequently, the pressure and the water level of the pressurizer have a slight increase. Subsequently, with the farther decrease of the core power and the establishment of the natural circulation of the three loops, they begin to decrease slowly.

At the initial transient stage, the sudden closure of the main steam valves as well as the higher heat transferred to the secondary side of the steam generator than that removed by the residual heat exchanger (see Figure 5) causes a rapid increase of the secondary loop pressure as shown in Figure 7. With the establishment of the natural circulation of the three loops, it begins to decrease slowly. It is noted that the peak value of the secondary loop pressure is very high without considering the overpressure protection. Thus, a pressure protection measure should be included to prevent the secondary loop pressure exceeding the acceptable value. The mass flow rate of the secondary loop is also shown in Figure 7. After the PRHRS starts up, the water in it immediately enters into the steam generators, which causes a rapid increase of the mass flow rates in the heat exchanger. The cold water in the shell-side of the heat exchanger is heated gradually after the high-temperature fluid from the steam generator enters the tube-inside of the heat exchanger. At about 40 seconds, the outlet fluid temperature of the third loop reaches its maximum value as shown in Figure 7. Correspondingly, the transient behavior of the third loop mass flow rate is similar to the outlet fluid temperature of the third loop (see Figure 7). Figure 7 also shows that the establishment of the natural circulation in the third loop needs a period of time (about 40 seconds). After reaching 


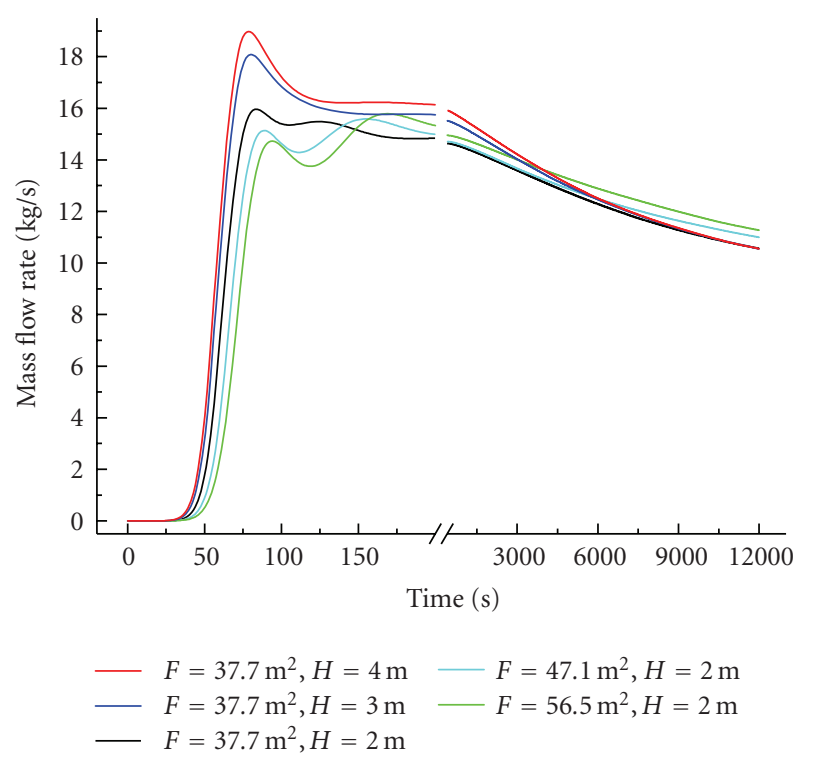

Figure 8: Mass flow rates of the third loop with different height differences and heat transfer areas.

their peak values, they start to decrease slowly with the decrease of the heat transferred to the third loop.

6.2. Effect of Parameter on the Characteristics of PRHRS. Height difference, between the steam generator and the heat exchanger, and the heat transfer area of the heat exchanger are the two main parameters affecting the thermal hydraulic characteristics of the PRHRS. The effects of these two factors are investigated in this paper. The variation of the heat transfer area of the heat exchanger is carried out through changing the number of the heat transfer tube without changing their length.

The mass flow rates of the third loop with different height difference and heat transfer area are shown in Figure 8. F is the heat transfer area of the heat exchanger, while $H$ is the height difference between the steam generator and the heat exchanger in Figure 8. It shows that the higher the height difference between the steam generator and the heat exchanger, the easier the establishment of the natural circulation in the water pool and the larger the peak value of the mass flow rate. The initial capacity of the cold water in the tube-inside of the heat exchanger increases with the increase of the heat transfer area of the heat exchanger, which leads that the time when the fluid with high temperature from the steam generator replaces the initial cold water is longer with larger heat transfer area (see Figure 9). Correspondingly, the smaller the heat transfer area of the heat exchanger, the earlier the outlet fluid temperature of the third loop reaching its maximum value as shown in Figure 10. Therefore, with the decrease of the heat transfer area, the establishment of the natural circulation in the water pool becomes earlier (see Figure 8).

The pressure of the secondary loop and the pressurizer are shown in Figures 11 and 12, respectively. The peak value

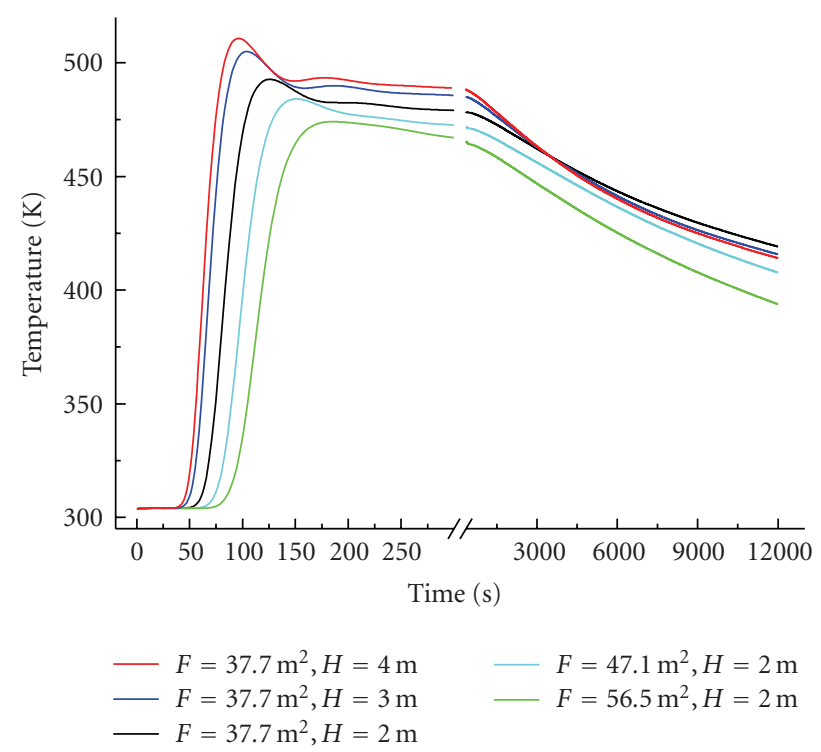

FIGURE 9: Outlet fluid temperature in the heat exchanger of the secondary loop with different height differences and heat transfer areas.

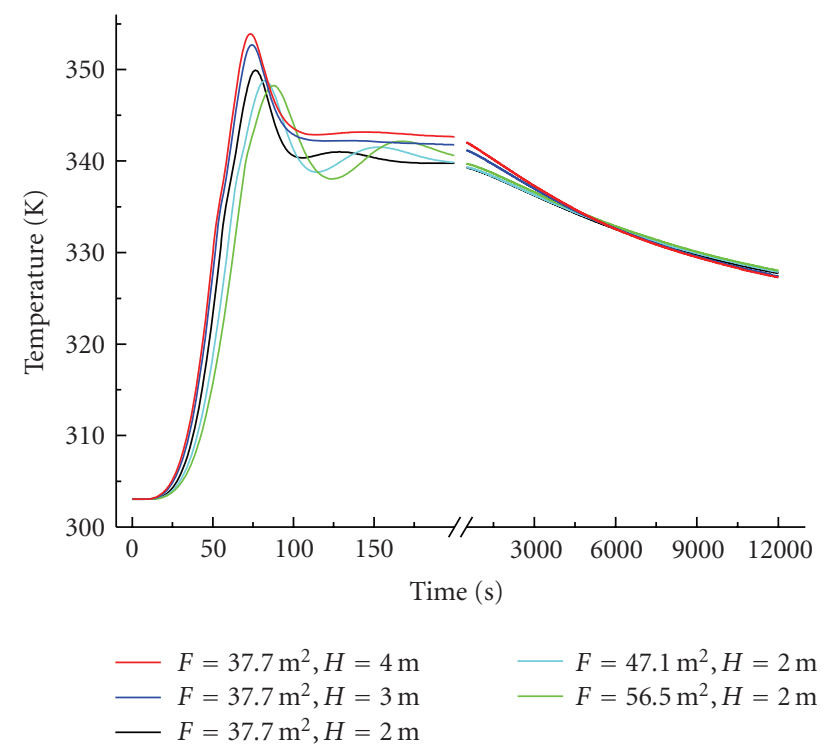

Figure 10: Outlet fluid temperature of the third loop with different height differences and heat transfer areas.

of the secondary loop pressure decreases with the increase of the height difference between the steam generator and the heat exchanger, and increases with the increase of the heat transfer area of the heat exchanger. Figure 11 also indicates that the effects of the height difference between the steam generator and the heat exchanger on the pressure of the secondary loop is larger than that of the heat transfer area of the heat exchanger. For the pressure of the pressurizer, the higher the height difference between the steam generator and the heat exchanger and the larger the transfer area of the 


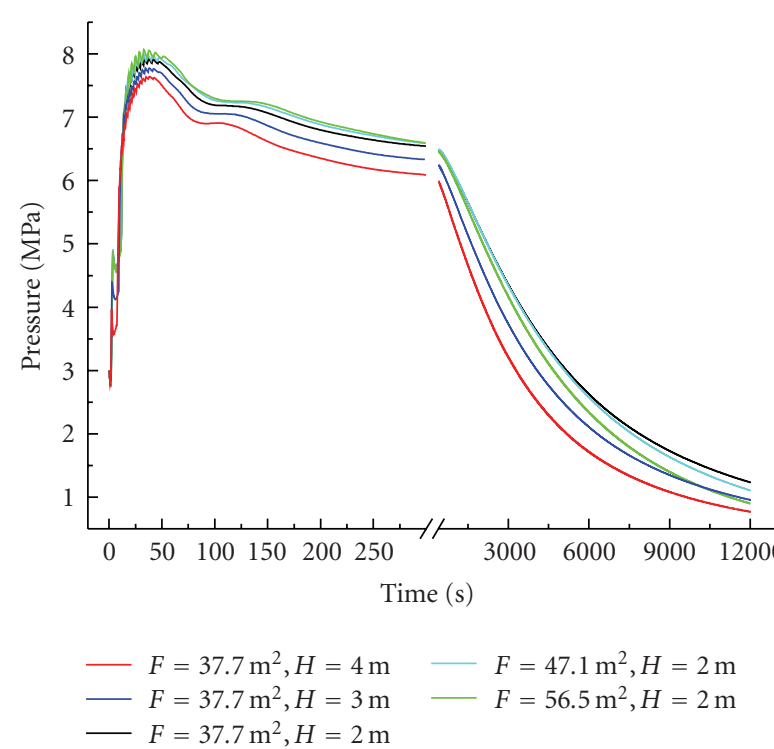

Figure 11: Pressure of the secondary loop with different height differences and heat transfer areas.

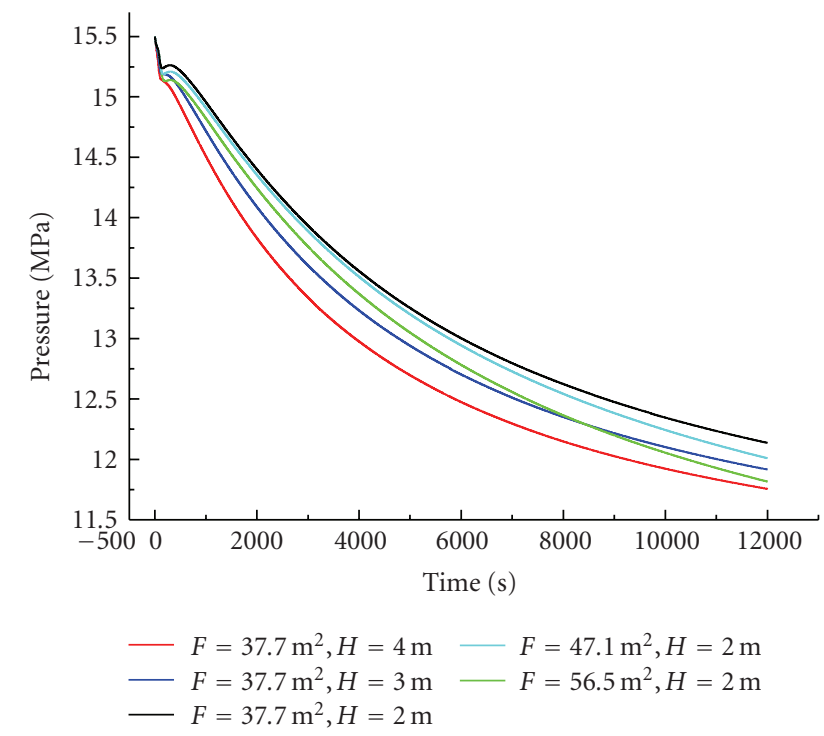

Figure 12: Pressure of pressurizer with different height differences and heat transfer areas.

heat exchanger, the quicker the decrease of it (see Figure 12). Consequently, the higher height difference between the steam generator and the residual heat exchanger and the larger heat transfer area of the residual heat exchanger are favorable to the passive residual heat removal system.

\section{Conclusions}

A theoretical one-dimensional model and a simulation code (SCPRHRS) are developed to investigate the thermal hydraulic characteristics of a new type of PRHRS, connected to the reactor coolant system via the secondary side of the steam generators, for an integral PWR. The model is based on the fundamental conservation principles: the mass, momentum, and energy conservation equations. System component models are included according to the special design features of it. All possible flow and heat transfer conditions are considered and the corresponding optional models are supplied in the code.

The transient behavior of the PRHRS and the effects of parameters such as the height difference between the steam generator and the heat exchanger and the heat transfer area of the heat exchanger are studied in detail. It is found that the calculated parameter variation trends are reasonable. The decay heat can be safely removed by the PRHRS. The higher height difference between the steam generator and the residual heat exchanger and the larger heat transfer area of the residual heat exchanger are favorable to the passive residual heat removal system. It is noted that the peak value of the secondary loop pressure is very high without considering the overpressure protection. Thus, a pressure protection should be included to prevent the secondary loop pressure exceeding the acceptable value. Also, experimental verification of the code as well as the model improvement is expected to be going on in the future since there is no experimental data can be adopted currently.

\section{Nomenclature}

$\begin{array}{ll}A: & \text { Cross-section area of the flow channel, } \mathrm{m}^{2} \\ B: & \text { Natural circulation driving head, } \mathrm{Pa} \\ c: & \text { Local form loss coefficient } \\ C_{p}: & \text { Specific heat, } \mathrm{kJ} /(\mathrm{kg} \cdot \mathrm{K}) \\ D_{e}: & \text { Hydraulic equivalent diameter of the flow } \\ f: & \text { channel, } \mathrm{m} \\ g: & \text { Griction coefficient } \\ h: & \text { Specific enthalpy, } \mathrm{kJ} / \mathrm{kg} \\ H: & \text { Heat transfer coefficient, } \mathrm{kW} /\left(\mathrm{m}^{2} \cdot \mathrm{K}\right) \\ L: & \text { Height of the residual heat exchanger, } \mathrm{m} \\ M: & \text { Fluid mass in the control volume, } \mathrm{kg} ; \\ p: & \text { Pressure, Pa } \\ T: & \text { Temperature, } \mathrm{K} \\ v: & \text { Specific volume, } \mathrm{m}^{3} / \mathrm{kg} \\ W: & \text { Mass flow rate, } \mathrm{kg} / \mathrm{s} \\ \Delta P_{f}: & \text { Friction pressure drop, Pa } \\ \Delta P_{\text {loc }}: & \text { Local pressure drop, Pa. }\end{array}$

\section{Greek letters}

$\begin{array}{ll}\rho: & \text { Fluid density, } \mathrm{kg} / \mathrm{m}^{3} \\ \tau: & \text { Time, } \mathrm{s} \\ \omega: & \text { Rotational speed, rps } \\ \Phi_{\text {tp }}^{2}: & \text { Two-phase frictional multiplier. }\end{array}$




\section{Subscripts}

1: $\quad$ The side of fluid with higher temperature

2: $\quad$ The side of fluid with lower temperature

in: Control volume inlet

lo: Total flow assumed liquid

$P: \quad$ Primary loop

$p: \quad$ Water pool

pump: Main coolant water pump

s: $\quad$ Secondary loop

$t$ : Third loop

tp: Two-phase flow

$v$ : $\quad$ By-pass valve

$w$ : Tube wall

\section{References}

[1] D. Adomaitis, G. Saiu, and M. Oyarzabal, "European passive plant program: a design for the 21st century," Nuclear Engineering and Design, vol. 179, no. 1, pp. 17-29, 1998.

[2] J. N. Reyes Jr. and L. Hochreiter, "Scaling analysis for the OSU AP600 test facility (APEX)," Nuclear Engineering and Design, vol. 186, no. 1-2, pp. 53-109, 1998.

[3] J. Zhang, S. M. Bajorek, R. M. Kemper, M. E. Nissley, N. Petkov, and L. E. Hochreiter, "Application of the WCOBRA/TRAC best-estimate methodology to the AP600 largebreak LOCA analysis," Nuclear Engineering and Design, vol. 186, no. 1-2, pp. 279-301, 1998.

[4] J. Hyvärinen, "Heat transfer characteristics of horizontal steam generators under natural circulation conditions," Nuclear Engineering and Design, vol. 166, no. 2, pp. 191-223, 1996.

[5] International Atomic Energy Agency, Status of Advanced Light Water Reactor Designs 2004, IAEA Tecdoc Series no. 1391, IAEA, Vienna, Austria, 2004.

[6] E. Krepper, "Pre- and post-test calculations to natural circulation experiments at the integral test facility ISB-VVER using the thermalhydraulic code ATHLET," Nuclear Engineering and Design, vol. 190, no. 3, pp. 341-346, 1999.

[7] S. K. Mousavian, F. D'Auria, and M. A. Salehi, "Analysis of natural circulation phenomena in VVER-1000," Nuclear Engineering and Design, vol. 229, no. 1, pp. 25-46, 2004.

[8] G. H. Su, Y. J. Guo, et al., "On natural circulation behaviors of passive decay heat removal," Journal of Xi'an Jiaotong University, vol. 29, pp. 38-49, 1995.

[9] G. H. Su, Y. Guo, H. Xie, D. N. Jia, and T. Zhou, "Thermohydraulic characteristics of integrated nuclear power plant," Journal of Xi'an Jiaotong University, vol. 34, no. 1, pp. 33-36, 2000.

[10] S. Z. Qiu, T. Zhou, Y. J. Guo, et al., "Modeling and dynamic simulation for emergency residual heat removal system for AC-600," A Chinese Journal of Nuclear Power Engineering, vol. 20, pp. 142-147, 1999.

[11] X. Zejun, Z. Wenbin, Z. Hua, C. Bingde, Z. Guifang, and J. Dounan, "Experimental research progress on passive safety systems of Chinese advanced PWR," Nuclear Engineering and Design, vol. 225, no. 2-3, pp. 305-313, 2003.

[12] M. H. Chang, S. K. Sim, and D. J. Lee, "SMART behavior under over-pressurizing accident conditions," Nuclear Engineering and Design, vol. 199, no. 1-2, pp. 187-196, 2000.
[13] Y.-J. Chung, S. H. Kim, and H.-C. Kim, "Thermal hydraulic analysis of SMART for heat removal transients by a secondary system," Nuclear Engineering and Design, vol. 225, no. 2-3, pp. 257-270, 2003.

[14] Y.-J. Chung, S.-H. Yang, H.-C. Kim, and S.-Q. Zee, “Thermal hydraulic calculation in a passive residual heat removal system of the SMART-P plant for forced and natural convection conditions," Nuclear Engineering and Design, vol. 232, no. 3, pp. 277-288, 2004.

[15] Y.-J. Chung, H.-C. Kim, B.-D. Chung, M.-K. Chung, and S.Q. Zee, "Two phase natural circulation and the heat transfer in the passive residual heat removal system of an integral type reactor," Annals of Nuclear Energy, vol. 33, no. 3, pp. 262-270, 2006.

[16] T. Iwamura, Y. Murao, F. Araya, and K. Okumura, "A concept and safety characteristics of JAERI passive safety reactor (JPSR)," Progress in Nuclear Energy, vol. 29, supplement 1, pp. 397-404, 1995.

[17] O. B. Samoilov, V. S. Kuul, V. A. Malamud, and G. I. Tarasov, "Integral nuclear power reactor with natural coolant circulation. Investigation of passive RHR system," Nuclear Engineering and Design, vol. 165, no. 1-2, pp. 259-264, 1996.

[18] M. Peng, C. Ma, S. Bi, et al., "Two passive safety systems in a $200 \mathrm{MW}$ demonstration nuclear heating plant," Nuclear Engineering and Design, vol. 160, no. 1-2, pp. 213-220, 1996.

[19] Z. Jinling, G. Yujun, et al., "Influences of the passive emergence residual heat removed system upou the accident of loss of offsite power in nuclear power plant," Atomic Energy Science and Technology, vol. 31, no. 2, pp. 36-40, 1997.

[20] T. Kusunoki, N. Odano, T. Yoritsune, T. Ishida, T. Hoshi, and K. Sako, "Design of advanced integral-type marine reactor, MRX," Nuclear Engineering and Design, vol. 201, no. 2-3, pp. 155-175, 2000.

[21] Z. Xinian, G. Weijun, H. Bing, and S. Shifei, "Transient analyses of the passive residual heat removal system," Nuclear Engineering and Design, vol. 206, no. 1, pp. 105-111, 2001.

[22] M. D. Carelli, L. E. Conway, L. Oriani, et al., "The design and safety features of the IRIS reactor," Nuclear Engineering and Design, vol. 230, no. 1-3, pp. 151-167, 2004.

[23] J. G. Collier and J. R. Thome, Convective Boiling and Condensation, Oxford University Press, Oxford, UK, 3rd edition, 1994.

[24] Y. Pingan, Z. Ruian, Y. Zhenwan, and S. Xiuzhong, Nuclear Reactor Thermal Hydraulics, Shanghai Jiao Tong University Press, Shanghai, China, 2001.

[25] W. X. Tian, S. Z. Qiu, Y. Guo, G. H. Su, and D. N. Jia, "Development of a thermal-hydraulic analysis code for CARR," Annals of Nuclear Energy, vol. 32, no. 3, pp. 261-279, 2005.

[26] W. Tian, S. Qiu, G. H. Su, D. N. Jia, X. Liu, and J. Zhang, "Thermohydraulic and safety analysis on China advanced research reactor under station blackout accident," Annals of Nuclear Energy, vol. 34, no. 4, pp. 288-296, 2007.

[27] J. G. Collier, Convective Boiling and Condensation, McgrawHill, New York, NY, USA, 2nd edition, 1981.

[28] F. P. Incropera and D. P. DeWitt, Introduction to Heat Transfer, John Wiley \& Sons, New York, NY, USA, 1985.

[29] D. C. Groeneveld, L. K. H. Leung, A. Z. Vasic, Y. J. Guo, and S. C. Cheng, "A look-up table for fully developed film-boiling heat transfer," Nuclear Engineering and Design, vol. 225, no. 1, pp. 83-97, 2003.

[30] M. M. Shah, "A general correlation for heat transfer during film condensation inside pipes," International Journal of Heat and Mass Transfer, vol. 22, no. 4, pp. 547-556, 1979. 
[31] J. J. Xu and D. N. Jia, Boiling Heat Transfer and Two-Phase Flow, Atomic Energy Press, Beijing, China, 2001.

[32] D. Chisholm, "Pressure gradients due to friction during the flow of evaporating two-phase mixtures in smooth tubes and channels," International Journal of Heat and Mass Transfer, vol. 16, no. 2, pp. 347-358, 1973.

[33] Y. Zhaoding, Algorithm for Initial Value Problem of Rigid Ordinary Differential Equations, Science Press, Beijing, China, 1987.

[34] G. H. Su, D. N. Jia, K. Fukuda, and Y. Guo, "Theoretical study on density wave oscillation of two-phase natural circulation under low quality conditions," Journal of Nuclear Science and Technology, vol. 38, no. 8, pp. 607-613, 2001.

[35] G. Yun, G. H. Su, J. Q. Wang, et al., "Two-phase instability analysis in natural circulation loops of China advanced research reactor," Annals of Nuclear Energy, vol. 32, no. 4, pp. 379-397, 2005. 

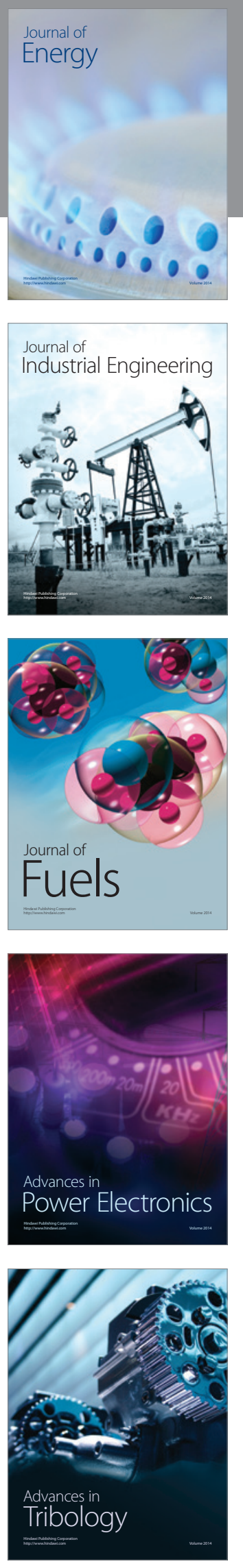
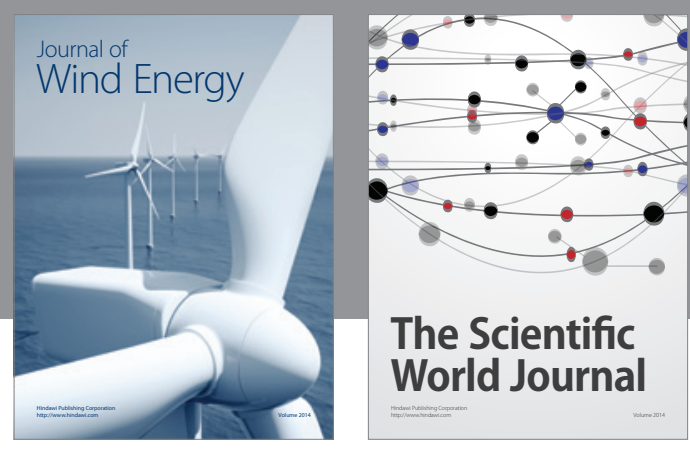

The Scientific World Journal

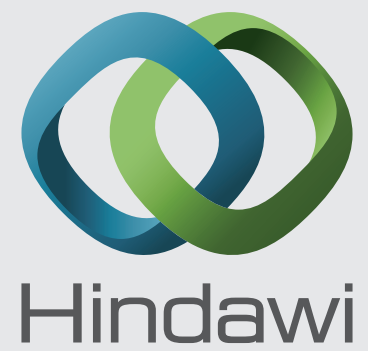

Submit your manuscripts at http://www.hindawi.com
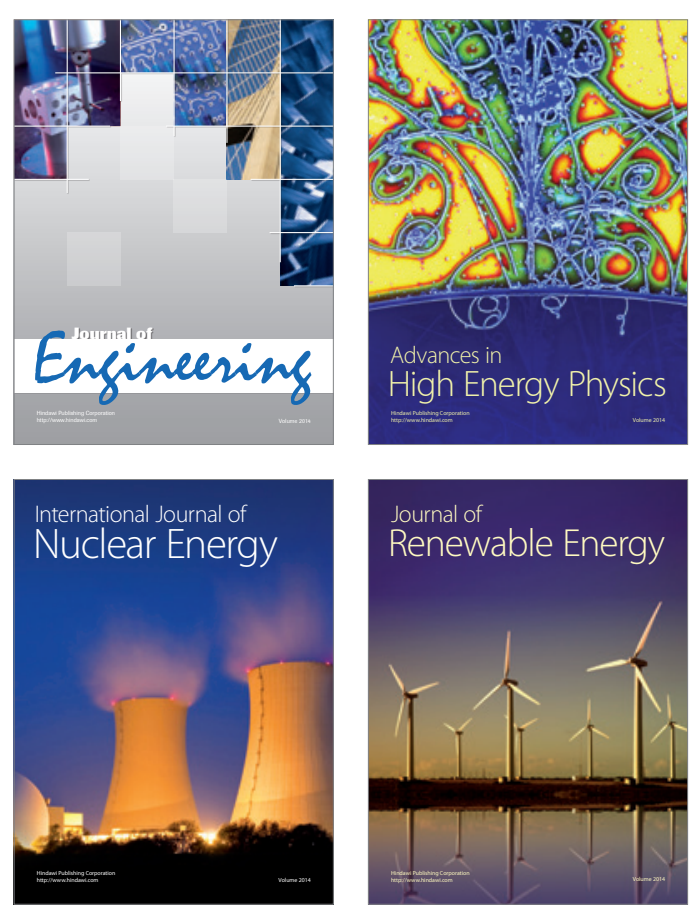

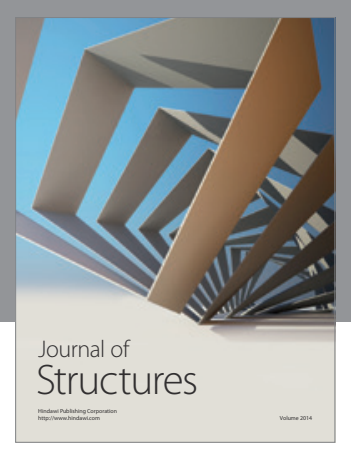

Rotating
Mechinery
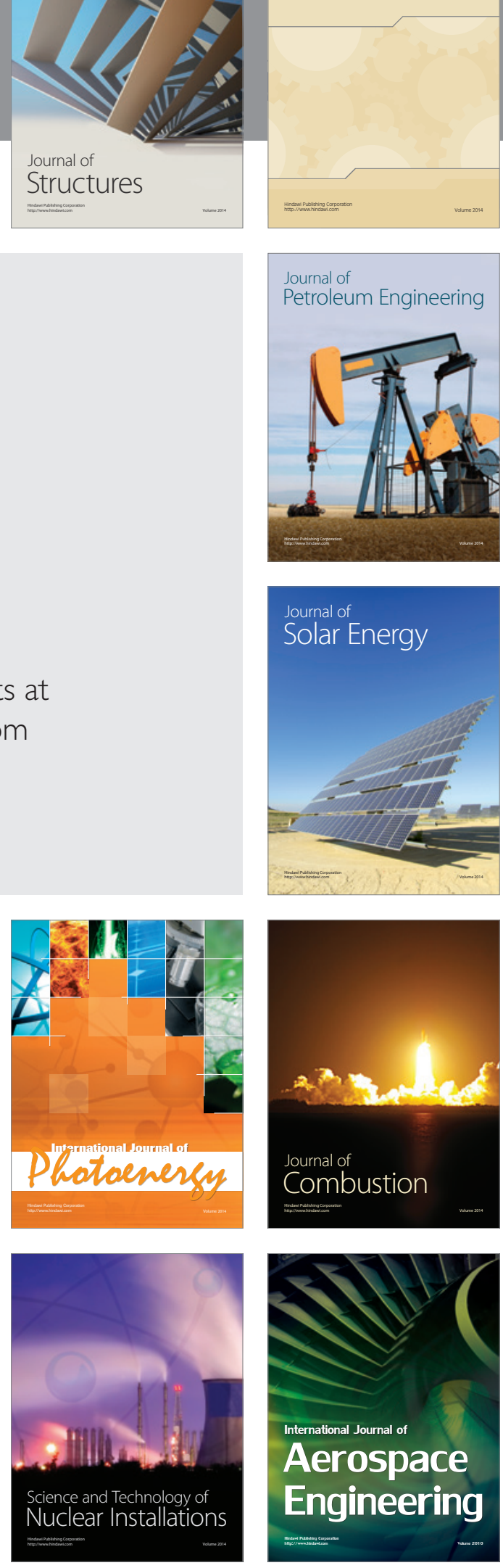